\title{
An empirical analysis of public and private medical practice in Australia
}

\author{
Terence Chai Cheng ${ }^{1}$, Catherine M Joyce ${ }^{2}$, Anthony Scott ${ }^{1}$ \\ ${ }^{1}$ Melbourne Institute of Applied Economic and Social Research, The University of Melbourne \\ ${ }^{2}$ Department of Epidemiology and Preventive Medicine, Monash University
}

\begin{abstract}
The combination of public and private medical practice is widespread in many health systems and has important consequences for health care cost and quality. However, its forms and prevalence vary widely and are poorly understood. This paper examines factors associated with public and private sector work by medical specialists using a nationally representative sample of Australian doctors. We find considerable variations in the practice patterns, remuneration contracts and professional arrangements across doctors in different work sectors. Both specialists in mixed practice and private practice differ from public sector specialists with regard to their annual earnings, sources of income, maternity and other leave taken and number of practice locations. Public sector specialists are likely to be younger, to be international medical graduates, devote a higher percentage of time to education and research, and are more likely to do after hours and on-call work compared with private sector specialists. Gender and total hours worked do not differ between doctors across the different practice types.
\end{abstract}

Keywords: Public-Private Mix; Specialists; Medical workforce; Australia.

Text statistics: 4541 words, 2 tables in text. 1 table in Appendix

\section{Acknowledgements}

This work was supported by a National Health and Medical Research Council Health Services Research Grant (454799) and the Commonwealth Department of Health and Ageing. The views in this paper are those of the authors alone. We thank the doctors who gave their valuable time to participate in MABEL, and the other members of the MABEL team for data cleaning and comments on drafts of this paper. The study was approved by the University of Melbourne Faculty of Economics and Commerce Human Ethics Advisory Group (Ref. 0709559) and the Monash University Standing Committee on Ethics in Research Involving Humans (Ref. CF07/1102 - 2007000291). 


\section{Introduction}

The blurring of public and private domains in the financing and delivery of health care has occurred in many countries, a phenomenon that has been documented and commented through the perspectives of a variety of disciplines such as economics, geography, organisation research and law (e.g. Newbrander and Parker 1992; Brown and Barnett 2004; Anderson 2012; Flood and Thomas 2010). Cost constraints on public health care budgets have encouraged governments to look towards a greater role of private financing. In countries where the public sector traditionally plays a dominant role, there is increasingly greater involvement by the private sector in the delivery of health care, engaging with public purchasers and providers in both a collaborative and competitive fashion.

The increasing public and private interface has generated considerable interest on the combination of public and private practice by medical practitioners. This phenomenon, often referred to as physician dual practice, is widespread in many developing and developed countries. For countries with a large public sector, the interest in dual practice stems from concerns on whether private financing divert resources away from the public health care system (Tuohy et al 2004). More broadly, dual practice has important implications for health care cost and quality that are both positive (e.g. increasing job quality, recruitment and retention) and negative (e.g. diversion of more healthy patients into private practice) (see Garcia-Prado and Gonzalez (2011) and Socha and Bech (2011) for recent reviews).

Given that many health systems have some combination of public and private sectors, governments who manage the public sector must therefore make decisions about the degree of regulation and/or incentivisation applied to medical practitioners' choice of 
whether, and how much, to work in each sector. The regulatory, policy, and financing settings in place in each country act to constrain or facilitate the choice of work sector (Garcia-Prado and Gonzalez 2007; Midtun 2007a).

Pecuniary and non-pecuniary characteristics of jobs have been shown to influence decisionmaking on choices of occupation, jobs, and work sector among medical professionals (e.g. Thornton and Esposto; Scott 2001; Saether 2005). Culture and peer group norms of the specialty also play a role (Midtun 2007b), as well as the preferences of medical practitioners driven by motivations including income, reputation/status, autonomy, and working with disadvantaged groups (Gruen et al. 2002; Humphrey and Russell 2004). Individual characteristics such as age and gender have also been found to be important (Kankaanranta et al. 2007).

A specific policy issue faced by many countries is medical workforce imbalance, such that for a given specialty there are shortages in the public sector workforce but not necessarily in the private sector. Thus, an important workforce policy issue is the need to attract and/or retain more doctors in the public sector to ensure access to government-funded medical care. The design of effective policy interventions to achieve this requires an understanding of the factors that can potentially influence doctors' decisions about how they allocate time across the sectors.

At present, however, there is a lack of research describing how, and to what extent, doctors combine public and private practice, and what factors are associated with the choices made by doctors in regard to sector/s of practice. The limited information that is available 
indicates significant variability in its prevalence even within developed countries (see GarciaPrado and Gonzalez 2011). This may stem from differences in the modalities of how doctors combine public and private sector work and how dual practice is defined, as well as being influenced by system-level factors as noted above. In addition, the evidence where available is often incomplete, covering only a subset of the medical workforce (e.g. internal medicine specialists). There is also little evidence on how institutional factors (e.g. the types of remuneration contracts and its sources), professional arrangements (e.g. contractual relationship with medical practice), specialty, and physician characteristics vary across doctors in different work sectors.

We contribute to the literature by answering the following research questions. What forms or configurations of combined public and private medical practice exist in Australia? How prevalent are these configurations? What are the differences in the characteristics of doctors who do public and/or private sector work? We address these questions using crosssectional data from a large nationally representative sample of Australian doctors. We focus on medical specialists since general practitioners in Australia operate largely in the private sector. We document the variations in institutional and professional arrangements, and investigate how personal and job characteristics, as well as medical specialty, vary with different practice arrangements.

The paper is structured as follows. The next section describes the context in Australia, including the financing, remuneration, and service provision arrangements in place. This is followed by a description of the methods used to collect and analyse empirical data about public and private practice by Australian medical specialists, and then presentation of the 
results. We conclude with a discussion of the policy implications with respect to mixed public-private practice.

\section{The context for mixed public and private practice in Australia}

Australia has a mixed public and private health care system. The universal health insurance system, Medicare, provides free or subsidised treatment by doctors and free public hospital treatment. Medical practitioners in private practice and private hospitals are free to charge patients what the market will bear, with a fixed subsidy from Medicare, resulting in varying patient co-payments. Private hospital expenses are mostly paid for through private health insurance, which is held by roughly half of the Australian population.

The definition of 'public' or 'private' may be distinguished by the ownership of hospitals and patients' source of funding but the boundaries of these domains are increasingly blurred. Public hospitals, owned and managed by jurisdictional governments, are allowed and even encouraged to admit private patients. With tight budgets, public hospitals have the incentives to shift costs onto the Federal government, by obtaining Medicare fee-for-service (FFS) payments (which are a Federal government responsibility) and thus earning higher revenue through encouraging patients to be treated privately. Private hospitals, which can be non-profit or for-profit, also treat a small proportion of public patients under contract with government. Both public and private hospitals increasingly compete for private patients. For instance, a large private hospital group in 2011 took an unprecedented step and revealed its performance on patients' outcomes (e.g. infection and repeated surgery rates) in attempt to lure private patients away from public hospitals. (Metherell 2011) 
In Australia, medical specialists can combine public sector work in public hospitals with private work in private hospitals and/or private consulting rooms. The type of practice arrangement by public specialists may vary, and is dependent on the terms of their employment agreement. Specialists who are salaried employees in public hospitals may be conferred the rights to private practice (RPP), and are entitled to charge private patients on a fee-for service basis. This private practice may be within their main employment setting (i.e., the hospital), and/or consulting practice outside of hospital; and/or work in a (different) private hospital setting. Specialists can also work primarily in private practice, from their own consulting rooms, or have admitting rights in a private hospital. These doctors can also work in public hospitals as Visiting Medical Officers (VMOs) on a contractual basis paid usually by fee-for-service or for each session.

Available data in Australia indicates that public hospitals employed 30,576 salaried medical officers in 2008-09 (AIHW 2010a), equivalent to about 45\% of the total medical labour force in Australia. If GPs (approximately 24,000), as well as non-clinicians (approximately 4600) are excluded; the employed public hospital doctor workforce represents around three quarters of the remaining doctors (who comprise hospital non-specialists, specialists, and specialists in training) (AIHW 2010b). It is not known how many specialists work full time in the public hospital setting. There are no national data indicating what proportion of these doctors also work in private practice, and no data on the number of doctors working solely in private practice. There are no data collections indicating the number of doctors who have the right to admit patients, either to public or private hospitals (Productivity Commission 2009). In short , there is no national information describing the nature of doctors' cross-sector work in Australia, and significant gaps in knowledge about the prevalence or nature of mixed public and private practice arrangements. 
Like many other countries, Australia has been experiencing medical workforce shortages for some time, and these have particularly impacted on rural and remote areas of the country, and on public hospitals. A wide range of strategies have been initiated by the Australian government in response, including recruitment of International Medical Graduates (IMGs). ${ }^{1}$ The government is able to regulate and constrain the practice of this group of doctors, and accordingly (because they are required to), the majority of IMGs work in rural and remote settings or public hospitals (Carver 2008). Australia has a stated policy of national selfsufficiency for its medical workforce (Australian Health Ministers Conference 2004), but this continues to be an aspiration rather than a reality.

While national medical workforce planning and policy has devoted extensive time and energy to rural and remote shortages, little consideration has been given to the distribution of doctors between the public and private sectors. This lack of attention to sectoral imbalance may be partly related to a lack of relevant data, so that the dimensions of the issue, and the potential to develop effective policy responses, is not yet well understood. However, this issue of shortages and surpluses of medical specialists across different specialties has recently been raised in Australia, including imbalances across the public and private sectors. Rather than simply training more specialists, there is now a recognition that the distribution of specialists across geography, sector, and speciality is a key future policy issue (Health Workforce Australia 2012).

\footnotetext{
${ }^{1}$ International medical graduates (IMGs) are doctors who have obtained their basic medical qualification in a medical school outside of Australia. IMGs must be successfully assessed by the Australian Medical Council or the relevant specialist college in order to practice as a medical specialist in Australia. Many are subject to restrictions on their location of practice.
} 


\section{Methodology}

We use data from the first wave (2008) of the "Medicine in Australia: Balancing Employment and Life (MABEL)" longitudinal survey of doctors. The methods for the MABEL survey have been reported in detail elsewhere (Joyce et al. 2010). A total of 10,498 doctors form the baseline cohort, which includes 4,597 specialists. The cohort was found to be nationally representative with respect to age, gender, doctor type, geographic location and hours worked (Joyce et al. 2010).

The survey questionnaire covered topics such as job satisfaction and attitudes to work; characteristics of work setting; hours worked; finances; demographics and family circumstances. Practice arrangements of specialists were described using information on weekly hours worked in public and private hospitals, private rooms and other settings (e.g. community health centre, tertiary education institution). Using this information, we classify the practice arrangements in three categories: public sector (public hospital only); private sector (private consultation rooms and/or private hospitals only); and both public and private sector or mixed practice (public hospitals, private hospitals and/or private consultation rooms). Doctors who reported having a majority number of hours in the 'Other' setting were excluded from the analysis sample. However, the final sample used in the analysis may include specialists who work one or more hours per week in the 'Other' settings.

In the above categorisation of practice arrangements, the 'public sector' category includes specialists who do not work in either private hospitals or private consulting rooms, but work in public hospitals with rights to private practice. This is contrary to the usual definition 
adopted in the dual practice literature (e.g. Garcia-Prado and Gonzalez (2007), which classifies such doctors as dual practicing physicians. It is important to highlight that in the Australian context, while public specialists with private practice privileges are allowed to treat private patients in public hospitals, often they may not in fact do so. These physicians can opt to receive a salary loading under their RPP contracts, and forgo any rights to retain fees accruing from the treatment of private patients.

\section{Analysis}

We first analyse the frequency of specialists by practice arrangements, namely whether doctors work in the public sector, private sector or both. Practice arrangements are further disaggregated by classifying whether specialists' main place of work (where doctors devote the majority of their time) is a hospital or non-hospital setting. We describe the types of remuneration contracts that apply for hospital specialists and on the business relationship with their private consulting medical practice for non-hospital specialists.

We then undertake a multivariate regression analysis to investigate the factors associated with specialists' practice arrangements. A multinomial logit model is used because the practice arrangement outcome variable is a three-category unordered variable. In the regression, public sector practice is designated as the reference category. We used an extensive and detailed set of covariates that describe doctors' personal and job characteristics, finances (e.g. income, sources of income), specialty and geography. We report the regression estimates as relative risk ratios, which is calculated as the ratio of the probability of choosing practice arrangement $j(j=$ private, mixed) over choosing public sector practice across two groups of doctors. For example, a coefficient of relative risk ratio 
that is less than 1 on the IMG indicator means that the probability that IMGs choose private practice relative to public practice is smaller than that for non-IMGs.

\section{Results}

\section{Descriptive statistics and sample selection}

Listwise deletion was applied to prepare the data for analysis. The variables (top five by frequency) and the corresponding number of observations (in brackets) dropped due to missing or incomplete information are as follows: Annual earnings (1029); financial sources (483); public and private practice status (445); number of practice locations (123); number of patients seen per week (120). The number of observations with complete data for analysis is $2,246 .{ }^{2}$ In the results on the distribution of practice types, remuneration contracts and business relationships, all reported proportions are adjusted using sampling weights to produce estimates that are representative to the population of specialists in Australia. The sampling weight included in the MABEL data is the inverse of the probability that a given observation is in the Wave 1 sample. The reference population data is the population frame containing all doctors in Australia obtained from the Australian Medical Publishing Company. See Yan et al (2010) for more details.

In the analysis sample consisting of 2,246 specialists, 729 doctors (32.7\%) work solely in the public sector. A total of 419 doctors (19.2\%) work solely in private sector, of which $29 \%$ work mainly in hospitals and $71 \%$ mainly in private consulting rooms. A total 1,098 doctors

\footnotetext{
${ }^{2}$ Analysis using a probit model of observations with non-complete data shows that doctors who are younger, those who see a lower number of patients per week, those who have taken a lower number of weeks off due to holiday and maternity reasons, and whose specialties are pathology and psychiatry are less likely to be in the analysis sample.
} 
(48.1\%) are in mixed sector practice. Of these specialists, 463 work predominantly (as measured by $\geq 50 \%$ of weekly working hours) in public hospitals and devote some hours in either private hospitals or private consulting practices. A total of 245 mixed practice doctors work mainly in private hospitals and 390 mainly in private consulting practices.

[Insert Table 1 about here]

\section{Remuneration contracts and business relationships}

Panel A of Table 1 presents the type of remuneration contracts by specialists' practice arrangements for those who work predominantly in hospitals. The results show that salaried positions are significantly more common in the public sector while fee-for-service payments are more prevalent in the private sector. For instance, $89.1 \%$ of public sector hospital specialists are remunerated on salaried contracts; with $(49.4 \%)$ or without $(39.7 \%)$ rights to private practice. For mixed practice specialists who work mainly in public hospitals, the proportion of doctors on salaried contracts $(70.8 \%)$ is lower than that for public-only specialists, with the difference largely attributed to a lower number of salaried positions with no rights to private practice in the latter group. In contrast to public sector specialists, the fraction of private sector doctors on salaried contracts is very low. $87.1 \%$ of private sector hospital specialists and $55.3 \%$ of mixed practice specialists who work mainly in private hospitals are remunerated via fee-for-service.

There are a few other interesting observations that arise from Table 1. Firstly, a very small percentage of public sector hospital doctors indicated that they are remunerated via fee-forservice. These doctors are providing their services to privately admitted patients in public hospitals by fee-for-service. If these doctors, together with public hospital doctors with RPP, 
are considered to be in mixed practice, then the proportion of specialists undertaking mixed practice rises to $65.7 \%$. Secondly, the proportion of dual practising hospital specialists paid on sessional or hourly rates is slightly higher compared with public-only specialists. This is likely a result of a higher proportion of visiting medical officers who provide services to public hospitals as independent contractors. Thirdly, a small number of mixed practising doctors in public and private hospitals are on salaried contracts with no rights to private practice. Although these doctors are not conferred the right to private practice within the terms of their employment, they may conduct private practice in either a different hospital or private consulting suite.

We mentioned above that in the Australian context, public specialists with private practice privileges often do not treat any private patients in public hospitals. In the sample of 369 public hospital specialists with RPP contracts, 231 (63\%) doctors have $0 \%$ of their income from private patient billings. These specialists are most likely those who have opted to receive a salary loading under their RPP contracts, in exchange for the rights to retain any income from private patients. For the remaining 138 (37\%) specialists, private billings account for an average of $20 \%$ of their annual income.

The nature of employment or engagement that non-hospital specialists have with their private consulting medical practice is shown in Panel B of Table 1. Private sector only doctors are less likely to be principal/partners or associates and more likely to be solo practitioners or contracted employees, compared to mixed practice doctors. Those who work in the private sector only are more likely to be salaried or contracted. 
[Insert Table 2 about here]

\section{Factors associated with choice of practice arrangement}

Table 2 presents the relative risk ratios (RRR) from the multinomial logit regression of private and mixed practice, in which public sector is the reference category. The summary statistics of the covariates of interest are shown in Table A1 of Appendix A. In terms of personal characteristics, the results suggest that mixed practice is not significantly associated with doctors' gender. Being in private practice is more likely for older doctors, with the likelihood of being in private-only practice over public-only practice increasing by $3 \%$ for each year of age. There is however no significant association between undertaking mixed practice and specialists' age. International medical graduates are considerably less likely to be in the private sector compared with public sector. There are no statistically significant associations between mixed practice and qualifications such as fellowship and postgraduate qualifications.

Practice arrangements are significantly associated with doctors' work characteristics. Private sector doctors are significantly less likely to undertake after hours or on-call work, and are less likely to travel and provide services in other geographic areas. Both private and mixed sector doctors have a higher number of practice locations and have a lower number of weeks away from work for maternity reasons. In addition, both private and mixed practices are not significantly associated with work hours or the number of patients seen per week, which collectively suggest that there are no significant differences in doctors' productivity across the three practice arrangements after allowing for other factors. 
In terms of remuneration, being in private and mixed practices is more likely for doctors with higher earnings, with the likelihood of being in private/mixed practices over public practice increasing by $0.2 \%$ for each $\$ 1000$ increase in annual earnings. Private and mixed practice doctors derived a larger fraction of their income from patient payments (both Medicare and non-Medicare), whereas public sector specialists are remunerated to a larger extent via salaries and other payments for hospital work compared to private sector specialists.

The specialty field of General Medicine is more likely to have specialists in mixed practice relative to public sector. Anaesthetists, Pathologists, Psychiatrists and specialists whose specialty area is 'Other' (e.g. rehabilitation medicine, radiation oncology) are more likely to be in private practice. There is a degree of association between geographic location and the propensity for public or private work. Specialists in Western Australia are more likely to combine public and private practice compared with those from New South Wales while those in Queensland and Western Australia are more likely to be engaged in only private work relative to New South Wales. The remoteness of doctors' practicing location is however not significantly associated with the sector of work.

We considered an alternative specification in the regression analysis where public hospital specialists remunerated via FFS and on salaried contracts with RPP are defined as mixed practice doctors. The regression estimates obtained are broadly similar with a small number of exceptions. A notable difference is that private practice is significantly associated with a lower number hours worked under the alternative specification, where previously we observe no differences across practice arrangements. In addition, mixed practice is 
significantly associated with higher rates of after-hours or on-call work. Some differences in the association of practice arrangements by states are also observed.

\section{Discussion}

In this study, we found that almost half of Australian specialists combine both public and private sector work. Roughly $20 \%$ work only in the private sector, with over $70 \%$ of these working in private consulting rooms. Of the $33 \%$ who work only in the public sector, almost $49 \%$ have rights to private practice. Of those in mixed practice but who work in public hospitals most of the time, $58 \%$ are paid by salary with rights to private practice. These observations support the notion that there is variety and complexity in the nature of medical practice in Australia.

As mentioned in the introduction, there are significant variations in the extent of dual practice across different countries with mixed public and private systems. For instance, over $90 \%$ of senior specialists in public hospitals have private practice privileges in Ireland (Wiley 2005) while only around $20 \%$ of doctors in Spain hold two jobs (Dolado and Felguerososo 2007). These variations may be a result of differences in how dual practice is defined, how the data is collected, and the types of medical practitioners that were investigated. For instance, we explained that in Australia, which shares many similarities with the Irish health care system, the majority of public hospital specialists with private practice privileges do not treat private patients. It appears that such privileges are a standard condition of many public hospital employment contracts but are not exercised by a large proportion of doctors to whom they are available. 
Beyond the aggregate measures on the prevalence of dual practice, what is less known is the varieties in the modes of how doctors combine public and private work, and the myriad institutional arrangements that exist within each system. In this regard, our research makes progress in clarifying these issues by indicating that, for example, in Australia fewer than half of all specialists have predominantly public work supplemented by private sector work. This highlights the need for more research to understand how dual practice is organised in different health systems.

This paper has documented key differences between doctors who work in different settings. Amongst others, we found that gender and total hours worked do not differ between doctors across the different practice types once other factors are controlled for. The finding on gender, which contrasts with previous research (e.g. Midtun 2007b, Kankaanranta et al. 2007), may be related to the different gender ratios within each specialty group. For example, only $11 \%$ of surgeons are female compared with $29 \%$ of specialists in Internal Medicine - Other. The age distribution is also different, with male specialists being on average older. Our result that private and mixed practices are associated with higher earnings is in line with with Midtun (2007b) and Gruen et al. (2002), who find that dual practice and private practice doctors have higher income.

We have confirmed different distribution of specialty fields by practice types, corroborating with Midtun (2007a). In Australia, some specialties are predominantly both public and private (e.g., most surgical specialties, Anaesthetics); while others are predominantly private (e.g., Pathology, Psychiatry). The differences between states and territories are suggestive of the role of public sector employment conditions, which differ between jurisdictions, in influencing practice type. 
This study has some limitations. We used cross-sectional data, and hence are restricted to examining associations, rather than causal relationships. Given the longitudinal nature of the study from which the data analysed here were drawn, potential exists to examine how doctors' choice of work sectors change over time as more waves of data become available. The current dataset also does not contain detailed information about workload by settings and the fee-paying status (public/private) of patients. This information will be essential if one is to be informed about how productivity varies across doctors remunerated through different mix of public and private patients.

Our study provides a description of public and private practice patterns and the factors associated with them in a setting where these issues are largely unregulated. Questions remain as to whether the current balance is appropriate. However, the extent to which recognised shortages and surpluses across specialties reflect imbalances across sectors within each specialty is a key issue to explore (HWA, 2012). Our results show that specialties recognised to be in shortage, such as general medicine and psychiatry, are more likely to have doctors who work in the private sector or mixed practice. Some specialties predicted to be in surplus, such as surgery, are also associated with more mixed sector working. Since our results suggest that the decision to work in both the public and the private sector is associated to a significant degree with institutional arrangements and medical specialty, it is likely to be difficult to influence those who work only in private sector, especially medical business owners, to spend some time in the public sector. Rather, the appropriate target for policy intervention would appear to be those already working in both sectors. For example, doctors may be encouraged to spend more time in public practice by increasing public sector remuneration relative to that in the private sector, which is in turn determined by the subsidies received from Medicare through the fee-for-service system, and by employer bargaining agreements that determine public sector pay and working conditions. 
Furthermore, given the importance of structural, systemic features in determining sector of practice, it follows that policy interventions may usefully be targeted at this level to influence practice patterns. Health Workforce Australia (2012) recently outlined a number of potential policy levers to address imbalances in the medical specialist workforce, some of which fall into this category. For example, they suggest that funding for specialty training programs can be better directed towards areas of shortage, and a combination of incentives and disincentives could be used to channel doctors into needed positions (e.g., those in the public sector).

Understanding that public sector shortages may not be due to overall workforce shortages, but rather to imbalances in the workforce, is an important pre-cursor to the development of effective policy responses. Both developed and developing countries face challenges in ensuring a sufficient public sector medical workforce to meet demand, and our study highlights the potential importance of understanding both the health system features which impact on practice patterns (which will be particular to each country) and the individuallevel factors influencing doctors' decision making. Further research is required to examine whether changes in policy can influence changes in the choice of work sectors. 


\section{References}

AlHW (2010a). Health expenditure Australia 2008-2009. AlHW Cat. No. HWE 51. Canberra, Australian Government Publishing Service.

AlHW (2010b). Medical labour force 2008. AlHW Cat. No. AUS 131. Canberra, Australian Government Publishing Service.

Australian Health Ministers Conference (2004). National health workforce strategic framework. Sydney, AHMC.

Anderson S. (2012). Public, private neither, both? Publicness theory and the analysis of healthcare organisations. Social Science and Medicine 74. 313-322.

Biglaiser, G., \& Ma, C. A. (2007). Moonlighting: public service and private practice. RAND Journal of Economics 38(4), 1113-1133.

Brown, L. \& Barnett, J. R. (2004). Is the corporate transformation of hospitals creating a new hybrid health care space? A case study of the impact of co-location of public and private hospitals in Australia. Social Science and Medicine 58, 427-444.

Carver, P. (2008). Self sufficiency and international medical graduates - Australia.

Melbourne, National Health Workforce Taskforce.Dolado, J. J., \& Felguerososo, F. (2007). Occupational mismatch and moonlighting of Spanish physicians: do couples matter? Fundación de Estudios de Economía Aplicada Working Paper 26.

Flood C.M. \& Thomas, B. (2010). Blurring of the public/private divide: the Canadian chapter. European Journal of Health Law 17, 257-278.

Garcia-Prado, A., \& Gonzalez, P. (2007). Policy and regulatory responses to dual practice in the health sector. Health Policy 84, 142-152.

Garcia-Prado, A., \& Gonzalez P. (2011). Whom do physicians work for? An analysis of dual practice in the health sector. Journal of Health Politics, Policy and Law 36(2), 265-294.

Gonzalez, P. (2004). Should physicians' dual practice be limited? An incentive approach. Health Economics 13, 505-524.

Gruen, R., Anwar, R., Begum, T., Killingsworth, J., \& Normand, C. (2002). Dual job holding practitioners in Bangladesh: an exploration. Social Science and Medicine 54, 267-279.

Health Workforce Australia (2012). Health workforce 2025 - Volume 3: Medical specialties. Adelaide: HWA.

Humphrey, C., \& Russell J. (2004). Motivation and values of hospital consultants in southeast England who work in the national health service and do private practice. Social Science and Medicine 59, 1241-1250. 
Joyce, C. M., Scott A., Jeon S. H., Humphreys J., Kalb G., \& Leahy, A. (2010) The "Medicine in Australia: Balancing Employment and Life (MABEL)" longitudinal survey - Protocol and baseline data for a prospective cohort study of Australian doctors' workforce participation. BMC Health Services Research 10, 50 doi: 10.1186/1472-6963-10-50

Kankaanranta, T., Nummi T., Vainiomäki J., Halila H., Hyppölä H., Isokoski M., Kujala S., Kumpusalo E., Mattila K., Virjo I., Vänskä J., \& Rissanen P. (2007). The role of job satisfaction, job dissatisfaction and demographic factors on physicians' intentions to switch work sector from public to private. Health Policy 83, 50-64.

Metherell, M. (2011). Private hospital group goes online to lure patients. The Sydney Morning Herald. 5 November. Viewed 5 November.

<http://www.smh.com.au/national/health/private-hospital-group-goes-online-to-lurepatients-20111104-1mzxd.html>.

Midtun, L. (2007a). Medical specialists' allocation of working time. Health Policy 83, 114-127.

Midtun, L. (2007b). Private or public? An empirical analysis of the importance of work values for work sector choice among Norwegian medical specialists. Social Science and Medicine 64, 1265-1277.

Newbrander, W., \& Parker D. (1992). The public and private sectors in health: economic issues. International Journal of Health Planning and Management 7, 37-49.

Productivity Commission (2009). Public and Private Hospitals. Research Report. Canberra, Productivity Commission.

Saether E.M. (2005). Physician labour supply: The wage impact on hours and practice combinations. Labour 19, 673-703.

Scott A. (2001). Eliciting GPs' preferences for pecuniary and non-pecuniary job characteristics. Journal of Health Economics 20, 329-347.

Socha, K.Z. \& Bech M. (2011). Physician dual practice: A review of literature. Health Policy $102,1-7$.

Thornton, J. \& Esposto, F. (2003). How important are economic factors in choice of medical specialty? Health Economics 12, 67-73.

Tuohy C.H., Flood C.M. \& Stabile M. (2004). How does private finance affect public health care systems? Marshaling the evidence from OECD nations. Journal of Health Politics, Policy and Law 29(3), 359-396.

Wiley M. (2005). The Irish health system: developments in strategy, structure, funding and delivery since 1980. Health Economics 14, S169-S186.

Kuehnle D., Scott A., Cheng T., Jeon S-H., Sivey P., \& Leahy A. (2010). MABEL user manual: Wave 1 Release. Melbourne Institute of Applied Economic and Social Research, Melbourne. 
Table 1: Remuneration contracts and business relationships by practice status (\%) ${ }^{\mathrm{a}}$

\begin{tabular}{ccc}
\hline Public only & Private only & Mixed Practice \\
$(\mathrm{N}=729)$ & $(\mathrm{N}=123)$ & $(1,098)$ \\
\cline { 3 - 3 } & & Mainly Public Mainly Private \\
\hline
\end{tabular}

Panel A: Remuneration contract type for hospital-based specialists

$\begin{array}{lrrrr}\text { Fee-for-service } & 0.9 & 87.1 & 8.2 & 55.3 \\ \text { Sessional/Hourly } & 9.9 & 5.1 & 18.5 & 23.3 \\ \text { Salary with no RPP } & & & & \\ \text { Salary with RPP } & 39.7 & 3.1 & 12.9 & 3.7 \\ \text { Other } & 49.4 & 4.7 & 57.9 & 15.5 \\ \text { Number of observations } & 729 & 123 & 463 & 2.3\end{array}$

Panel B: Business relationship with private practice for non-hospital specialists

Principal or Partner

Associate

Independent and Solo

Practitioners

Salaried/Contracted

Employee

Locum

Number of observations
59.8

9.6

12.3

16.7

1.7

296
70.2

15.5

7.6

0.5

390

\footnotetext{
${ }^{a}$ Proportions are adjusted using sampling weights provided in the MABEL data and thus represent population proportions.

${ }^{\mathrm{b}}$ Rights to private practice (RPP).
} 
Table 2: Relative risk ratios (RRR) of factors associated with practice types (Base type: Public).

\begin{tabular}{|c|c|c|c|c|}
\hline \multirow[t]{2}{*}{ Variables } & \multicolumn{2}{|l|}{ Private } & \multicolumn{2}{|c|}{ Mixed Practice } \\
\hline & RRR & $\begin{array}{l}\text { Standard } \\
\text { Error }\end{array}$ & RRR & $\begin{array}{l}\text { Standard } \\
\text { Error }\end{array}$ \\
\hline Female & 1.410 & 0.410 & 1.260 & 0.240 \\
\hline Age & $1.030 * *$ & 0.014 & 1.000 & 0.009 \\
\hline Fellowship & 1.350 & 0.800 & 1.500 & 0.640 \\
\hline \multicolumn{5}{|l|}{ Number of other } \\
\hline postgraduate qualifications & 0.920 & 0.200 & 1.190 & 0.160 \\
\hline \multicolumn{5}{|l|}{ International Medical } \\
\hline Graduate & $0.470 * *$ & 0.150 & 0.770 & 0.160 \\
\hline Weekly hours worked & 0.990 & 0.010 & 1.010 & 0.007 \\
\hline \multicolumn{5}{|l|}{$\%$ time in education and } \\
\hline research & $0.970 * *$ & 0.014 & 1.000 & 0.007 \\
\hline Do after hours/on-call & $0.220 * * *$ & 0.071 & 0.720 & 0.190 \\
\hline Number of patients seen & 1.000 & 0.022 & 1.000 & 0.002 \\
\hline \multicolumn{5}{|l|}{ Number of practicing } \\
\hline locations & $1.220 * * *$ & 0.081 & $1.350 * * *$ & 0.070 \\
\hline \multicolumn{5}{|l|}{ Travel to provide services in } \\
\hline other areas & $0.590 * *$ & 0.150 & 0.910 & 0.160 \\
\hline \multicolumn{5}{|l|}{ Regular contribution to } \\
\hline superannuation & 1.050 & 0.690 & 2.020 & 1.210 \\
\hline Weeks leave for holiday & 0.980 & 0.040 & 0.990 & 0.023 \\
\hline \multicolumn{5}{|l|}{ Weeks leave for maternity } \\
\hline and other reasons & $0.920 * *$ & 0.031 & $0.940 * * *$ & 0.021 \\
\hline Annual earnings & $1.002^{*}$ & 0.001 & $1.002^{*}$ & 0.001 \\
\hline \multicolumn{5}{|c|}{ Sources of earnings (Reference: Other) } \\
\hline Medicare & $1.040 * * *$ & 0.009 & $1.060 * * *$ & 0.009 \\
\hline Non-Medicare & $1.090 * * *$ & 0.017 & $1.100 * * *$ & 0.016 \\
\hline
\end{tabular}




\begin{tabular}{|c|c|c|c|c|}
\hline Government incentives & 0.870 & 0.068 & 1.000 & 0.013 \\
\hline Hospital work & $0.910 * * *$ & 0.009 & 0.990 & 0.007 \\
\hline \multicolumn{5}{|c|}{ Specialty (Reference: Paediatrics) } \\
\hline Gastroenterology & 0.860 & 0.810 & 2.160 & 1.270 \\
\hline General medicine & 0.930 & 0.930 & $2.850 * *$ & 1.310 \\
\hline Internal medicine: Other & 1.510 & 0.890 & $1.640^{*}$ & 0.490 \\
\hline Pathology & $8.240 * * *$ & 8.570 & 0.870 & 0.540 \\
\hline General surgery & 2.290 & 1.840 & $3.830 * * *$ & 1.860 \\
\hline Orthopaedic surgery & 1.040 & 1.010 & 1.600 & 1.240 \\
\hline Surgery: Other & 2.760 & 2.100 & $4.270 * * *$ & 2.220 \\
\hline Anaesthetics & $3.790 * *$ & 2.290 & $2.240 * *$ & 0.750 \\
\hline Diagnostic radiology & 4.070 & 3.640 & 1.460 & 0.910 \\
\hline Emergency medicine & 8.320 & 12.490 & 0.580 & 0.250 \\
\hline Obstetrics & 3.870 & 2.750 & $2.310^{*}$ & 1.050 \\
\hline Ophthalmology & 5.230 & 7.910 & 4.140 & 5.820 \\
\hline Psychiatry & $10.620 * * *$ & 6.730 & 1.740 & 0.640 \\
\hline Other & $6.640 * * *$ & 4.190 & 1.570 & 0.550 \\
\hline \multicolumn{5}{|c|}{ State (Reference: New South Wales) } \\
\hline Victoria & 1.500 & 0.440 & 1.930 & 0.380 \\
\hline Queensland & $2.970 * * *$ & 1.080 & 0.860 & 0.220 \\
\hline Western Australia & $3.490 * * *$ & 1.550 & $2.160 * *$ & 0.690 \\
\hline South Australia & 0.820 & 0.350 & 0.720 & 0.200 \\
\hline Tasmania & 2.020 & 1.570 & 1.540 & 0.760 \\
\hline Australian Capital Territory & $4.240^{*}$ & 3.650 & 1.670 & 0.970 \\
\hline Northern Territory & 6.480 & 11.290 & 1.520 & 1.150 \\
\hline \multicolumn{5}{|c|}{ Remoteness (Reference: Major city) } \\
\hline Inner regional & 0.550 & 0.220 & 1.020 & 0.280 \\
\hline
\end{tabular}




$\begin{array}{lllll}\text { Other } & 0.330 & 0.240 & 0.910 & 0.430 \\ \text { Constant } & 0.500 & 0.790 & 0.019 & 0.230\end{array}$

***Significant at $1 \% ;{ }^{* *}$ Significant at $5 \% ; *$ Significant at $10 \%$. Null hypothesis in the test of significance for RR is whether the ratio is 1 . 


\section{University Library}

\section{- M M N E R VA A gateway to Melbourne's research publications}

Minerva Access is the Institutional Repository of The University of Melbourne

Author/s:

Cheng, TC;Joyce, CM;Scott, A

Title:

An empirical analysis of public and private medical practice in Australia

Date:

2013-06-01

Citation:

Cheng, T. C., Joyce, C. M. \& Scott, A. (2013). An empirical analysis of public and private medical practice in Australia. HEALTH POLICY, 111 (1), pp.43-51. https://doi.org/10.1016/ j.healthpol.2013.03.011.

Persistent Link:

http://hdl.handle.net/11343/115263 